\title{
EFEITOS DA INTOXICAÇÃO CRÔNICA COM O ETANOL NA EVOLUÇÃO DA TRIPANOSOMÍASE CRUZI EXPERIMENTAL NO CAMUNDONGO
}

\author{
Nildete das Graças Lima Gomes e Fausto Edmundo Lima Pereira
}

\begin{abstract}
Dois experimentos foram realizados para estudar o efeito da intoxicação crônica com o etanol (solução a 7\% como única fonte de líquido) sobre a evolução da infecção pelo T. cruzi em camundongos: (1) animais após 60 dias de infecção com cepa miotrópica do T. cruzi foram submetidos à intoxicação crônica com o etanol durante 6 meses; (2) animais cronicamente intoxicados com etanol durante 5 meses foram infectados com a mesma cepa do T. cruzi e, continuando a ingestão do etanol, foram acompanhados até 45 dias após a infecção. Os animais infectados e tratados com etanol apresentaram, em relação aos que não ingeriram álcool etílico: (a) mortalidade semelhante nos dois experimentos; (b) parasitemia mais alta na fase aguda e parasitemia patente mais freqüente na fase crônica; (b) miocardite com exsudato inflamatório menos intenso e fibrose miocárdica mais extensa na fase crônica; (c) no músculo esquelético, miosite menos intensa e arterite com trombose hialina menos freqüente.
\end{abstract}

Palavras-chaves: Alcoolismo e doença de Chagas. Alcoolismo. Trypanosoma cruzi.

O etilismo crônico é problema freqüente na população em geral, inclusive no Brasil, onde dados epidemiológicos, embora escassos, revelam alta freqüência ${ }^{14}$. Supõe-se, portanto, que nas regiões onde a doença de Chagas é endêmica, deve ser freqüente a ingestão do etanol. Como o etilismo crônico pode induzir lesões cardiacas no homem e em animais de laboratório 2356121332333435 além de interferir nos mecanismos de defesa do organismol, é possivel que possa também alterar a evolução da doença de Chagas.

Manigot e colaboradores ${ }^{29}$ estudando um grupo de chagásicos crônicos alcoólatras e não alcoólatras, encontraram número semelhante de pacientes assintomáticos (radiografia de tórax e eletrocardiograma normais) nos dois grupos; no entanto, a freqüência de xenodiagnósticos positivos foi maior no grupo etilista.

Em virtude da escassez de dados sobre os possíveis efeitos da ingestão do etanol na evolução da tripanosomiase americana, foi proposta a presente investigação com a finalidade de verificar os efeitos da intoxicação crônica com o etanol na evolução da infecção de camundongos com o $T$. cruzi.

Departamento de Patologia Centro Biomédico. Universidade Federal do Espírito Santo.

Endereço para correspondência: Dr. Fausto Edmundo Lima Pereira. Faculdade de Medicina da Universidade Federal do Espírito Santo. CP: 780-29000 Vitória, ES.

Recebido para publicação em 23/11/88.

\section{MATERIAL E MÉTODOS}

Foram utilizados camundongos albinos machos, não isogênicos, alimentados ad libitum com ração comercial Probiotério (Anderson Clayton, SP). Nos grupos infectados a inoculação foi realizada por via intraperitoneal, com cepa miotrópica do T. cruzi, isolada de um triatomíneo naturalmente infectado, originado do E. Santo. Os exames de parasitemia foram realizados pela método de Brener ${ }^{11}$, ou em gota espessa, sem volume conhecido, com contagem dos parasitos em até 150 campos de $400 \mathrm{X}$. O etanol foi administrado em solução a $7 \%$ como única fonte de líquido (etanol pro analysis, Merck). Foram realizados dois experimentos.

Experimento I. Para verificar os efeitos da intoxicação crônica pelo etanol em animais previamente infectados pelo $T$. cruzi. Os camundongos (27$31 \mathrm{~g}$ ) foram distribuidos nos seguintes grupos: grupo $T$. cruz $i$-etanol, de 12 animais que após 2 meses de infecção com $5 \times 10^{3}$ tripomastigotas, receberam a solução de etanol durante 6 meses; grupo $T$. cruz $i$ de 12 animais que foram infectados na mesma data e com o mesmo número de parasitas do grupo anterior mas que não receberam etanol; grupo etanol, de 12 animais que receberam o etanol durante 6 meses a partir da mesma data que os do grupo $T$. cruzi-etanol; grupo-controle de 6 animais que não foram infectados, nem ingeriram etanol. A parasitemia foi avaliada nos dias $15 \circ, 60$, 120 . $180{ }^{\circ}$ e $2400^{\circ}$ após a infecção.

Experimento II. Para verificar a susceptibilidade de camundongos intoxicados cronicamente com o etanol à infecção pelo T. cruzi. Dois grupos de 
Gomes NGL, Pereira FEL. Efeitos da intoxicacão crônica com o etanol na evolução da tripanosomiase cruzi experimental no camundongo. Revista da Sociedade Brasileira de Medicina Tropical 22: 191-197, Out-Dez, 1989.

camundongos ( 29 a $32 \mathrm{~g}$ ) foram assim distribuídos: grupo etanol $T$. cruzi II, de 8 animais que tratados com 0 etanol durante 6,5 meses foram infectados com $16 \times 10^{3}$ tripomastigotas no final do $5{ }^{\circ}$ mês. Grupo $T$. cruzi II, de 6 animais não tratados pelo etanol, que receberam o mesmo inóculo, na mesma data que o grupo anterior. A parasitemia foi medida diariamente até o $155^{\circ}$ dia de infecção e em dias alternados até o final do experimento (45 dias de infecção nos 2 grupos).

Os animais sobreviventes no final dos experimentos foram sacrificados e necropsiados. Fragmentos de músculo esquelético (quadriceps femural) e coração foram incluídos em parafina, cortados de forma semi-seriada (entre 20 e 30 cortes), corados pelas técnicas de hematoxilina-eosina, tricrômico de Mallory, hematoxilina fosfotungstica e Giemsa para tecidos. O exame microscópico foi dirigido para uma análise comparativa entre os grupos de cada experimento, em separado, no que se refere a distribuição, intensidade e qualidade das lesões.

Quando necessário foi utilizado o teste $t$ de Student para análise estatistica.

\section{RESULTADOS}

A solução de etanol a $7 \%$ foi bem aceita pelos animais e não ocorreram diferenças importantes em relação à ingestão da ração entre os diversos grupos, sendo pequenas as variações de peso corporal durante os experimentos (Tabela 1).

Experimento I. A mortalidade foi semelhante nos 2 grupos infectados. (Tabela 2 ). No final do experimento, após 6 meses de ingestão de etanol e 8 meses de infecção, $62,5 \%$ dos animais do grupo $T$. cruzietanol mostraram parasitas circulantes, fato observado em apenas $16,6 \%$ dos animais do grupo $T$. cruzi (Tabela 3). Exame macroscópico. Foi observado aumento de peso do coração nos 3 grupos experimentais em relação ao grupo-controle (Tabela 1). Exame microscópico. a) Grupc etanol (não infectado). No coração, hipotrofia e degeneração hidrópica e hialina segmentares de miocélulas e por vezes focos de necrose com exsudato de polimorfonucleares. Fibrose endomisial e perivascular discretas, com raros focos de espessamento endocárdico. Epicardite com exsudato mononuclear, sem comprometimento ganglionar e de fibras nervosas. No músculo esquelético, hipotrofia, necrose e inflamação discretas, com exsudação de polimorfonucleares. b) Grupo $T$. cruzi. No coração, inflamação caracterizada por exsudato de mononucleares, geralmente focal, comprometendo o pericárdio, miocárdio e endocárdio, mais intensa nos átrios e no ventriculo direito; ganglionite, periganglionite e perineurite em todos os animais (Figura 1). No músculo esquelético, focos extensos de miosite com exsudato mononuclear e polimorfonuclear, incluindo grande quantidade de eosinófilos e mastócitos; degeneração hialina, hipotrofia e centralização dos núcleos em algumas miocélulas. Lesões inflamatórias na parede das pequenas artérias e arteríolas, com necrose fibrinóide da parede e formação de trombos hialinos; neurite e perineurite com exsudato de mononucleares; não foram observados pseudocistos de amastigotas (Figura 2). c) Grupo T. cruzi-etanol. No coração, a inflamação mostrou extensão e distribuição semelhantes às do grupo infectado que não recebeu etanol, porém dois aspectos chamaram atenção: a fibrose endomisial foi mais intensa e havia maior número de polimorfonucleares no exsudato. As lesōes ganglionares e neurais foram semelhantres às do grupo não tratado pelo etanol (Figura 3). No músculo esquelético a miosite foi menos intensa, as lesões degenerativas mais acentuadas, e arterite e trombose foram muito menos freqüentes que no grupo não tratado com o álcool etílico (Figura 4). d) Grupo controle. No coraçāo, raros focos de miocitólise. No músculo esquelético, aspecto histológico normal.

Experimento II. No experimento II, o uso crônico do etanol não alterou a mortalidade, visto que nenhum animal morreu espontaneamente no periodo de 45 dias de infecção. No 14\% dia de infecção, 50\% dos animais do grupo etanol- $T$. cruzi II tinham parasitas circulantes, o que ocorreu em $20 \%$ dos animais pertencentes ao grupo T. cruzi II. A ascenção

Tabela 1 - Peso corporal e de órgãos, na infecção pelo $T$. cruzi, em camundongos com intoxicação crônica pelo etanol (Experimento I).

\begin{tabular}{|c|c|c|c|c|}
\hline Peso Grupos & T. cruzi & $\begin{array}{l}\text { T. cruzi-etanol } \\
\mathrm{X} \pm \mathrm{s}(\mathrm{g})\end{array}$ & Etanol & Controle \\
\hline Corporal inicial & $28,80 \pm 1,60$ & $28,60 \pm 1,20$ & $29,50 \pm 1,00$ & $28,00 \pm 1,80$ \\
\hline Corporal final & $29,90 \pm 1,10$ & $30,80 \pm 1,50$ & $31,80 \pm 1,90$ & $30,20 \pm 1,30$ \\
\hline Coração (médio) & $0,33 \pm 0,55^{*}$ & $0,27 \pm 0,04$ & $0,27 \pm 0,04$ & $0,23 \pm 0,02$ \\
\hline Fígado (médio) & $3,18 \pm 0,28$ & $2,50 \pm 0,42$ & $2,53 \pm 0,15$ & $2,55 \pm 0,13$ \\
\hline Baço (médio) & $0,51 \pm 0,11^{* *}$ & $0,43 \pm 0,09^{* *}$ & $0,25 \pm 0,08$ & $0,15 \pm 0,04$ \\
\hline
\end{tabular}

* diferença significativa em relação aos demais grupos $(\mathrm{p}<0,05)$

** diferença significativa em relaçào ao grupo controle $(p<0,05)$ 
Gomes NGL, Pereira FEL. Efeitos da intoxicação crônica com o etanol na evolução da tripanosomiase cruzi experimental no camundongo Revista da Sociedade Brasileira de Medicina Tropical 22: 191-197, Out-Dez, 1989.

Tabela 2 - Mortalidade na intoxicação crônica com o etanol em camundongos infectados com o $T$. cruzi.

\begin{tabular}{|c|c|c|c|c|c|}
\hline \multirow[t]{2}{*}{ Grupo } & \multirow[b]{2}{*}{60} & \multicolumn{3}{|c|}{ Dias após a infecção } & \multirow{2}{*}{$\begin{array}{c}\text { mortalidade } \\
\text { acumulada (\%) }\end{array}$} \\
\hline & & 120 & 180 & 240 & \\
\hline T. cruzi & $4 / 12$ & $4 / 12$ & $4 / 12$ & $6 / 12$ & 50,00 \\
\hline T. cruzi-etanol & $1 / 12$ & $2 / 12$ & $3 / 12$ & $4 / 12$ & 33,33 \\
\hline Etanol & $0 / 12$ & $0 / 12$ & $0 / 12$ & $2 / 12$ & 16,66 \\
\hline Controle & $0 / 6$ & $0 / 6$ & $0 / 6$ & $1 / 6$ & 16,66 \\
\hline
\end{tabular}

Tabela 3 - Parasitemia na intoxicação crônica pelo etanol de camundongos infectados com o T. cruzi.

\begin{tabular}{lccc}
\hline Grupo & N & Animais com parasitas & $\%$ \\
\hline$T$. cruzi & 6 & 1 & 16,6 \\
$T$. cruzi-etanol & 8 & 3 & 62,5 \\
\hline
\end{tabular}

Tabela 4 - Peso corporal e do coraçào, figado e baço, em camundongos infectados pelo T. cruzi, apos intoxicaçào crónica com etanol (Experimento II).

\begin{tabular}{lrr}
\hline Grupos & T. cruzi & Etanol-T. cruzi II \\
Peso & $\mathrm{X} \pm \mathrm{s}(\mathrm{g})$ & $\mathrm{X} \pm \mathrm{s}(\mathrm{g})$ \\
\hline Corporal (final) & $29,40 \pm 3,02$ & $32,10 \pm 3,10$ \\
Coração (médio) & $0,17 \pm 0,04$ & $0,22 \pm 0,05$ \\
Fígado (médio) & $1,57 \pm 0,33$ & $1,73 \pm 0,13$ \\
Baço (médio) & $0,42 \pm 0,21$ & $0,33 \pm 0,09$ \\
\hline
\end{tabular}
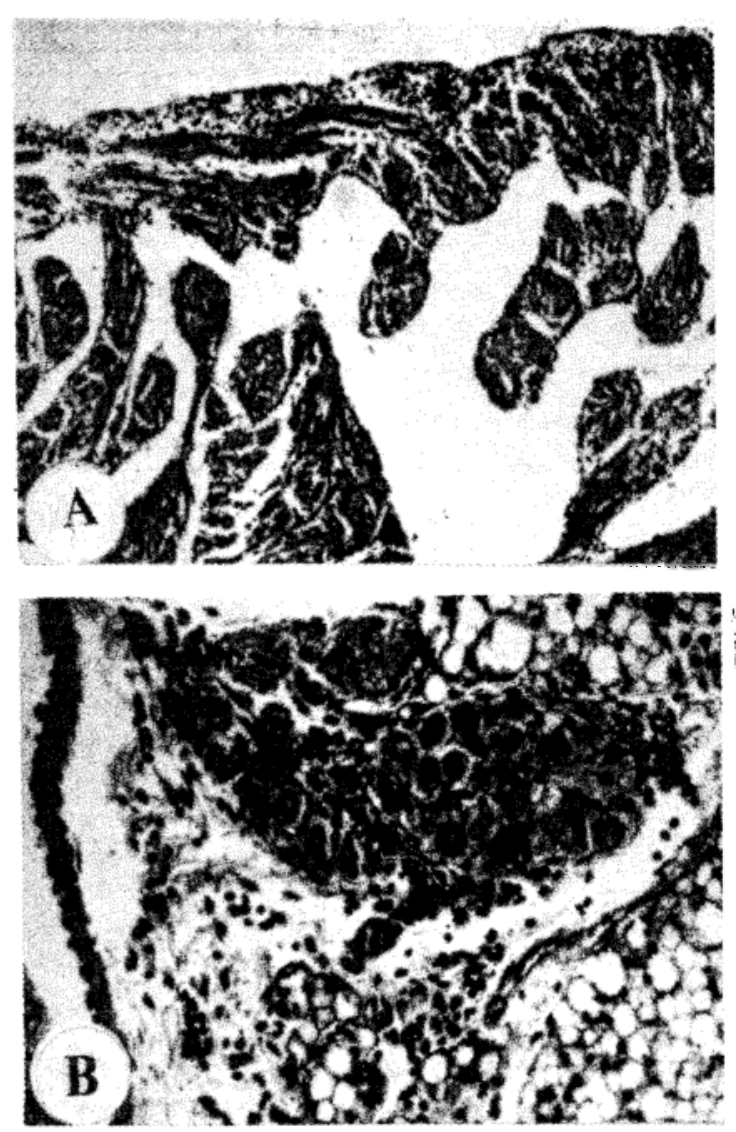

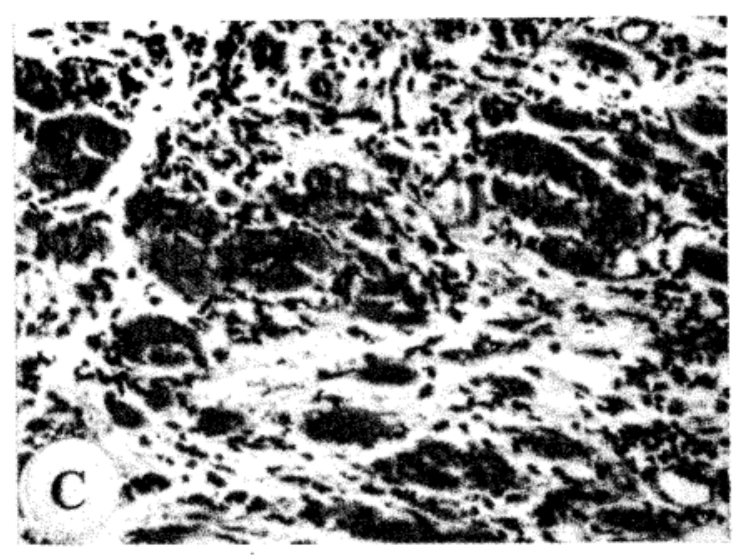

Figura 1 - Coração de camundongos infectados com $\mathrm{T}$. cruzi e que não ingeriram etanol. A: Epicardite, miocardite e endocardite focais nos átrios. $H E$ 40X. B: Gânglio epicárdico atrial com ganglionite e periganglionite. $H E 160 X$. C: Miocardite com exsudato de mononucleares no ventriculo direito. HE $160 X$.

da parasitemia foi também mais rápida no grupo que ingeriu etanol e, a partir do $15 \%$ dia de infecção, o número de tripomastigotas circulantes foi significativamente maior, mantendo-se assim até o final do experimento (Figura 5). O peso corporal e do coração, figado e baço estão relacionados na Tabela 4. Exame microscópico a) Grupo T. cruzi II. As lesões inflamatórias no coração e no músculo esquelético, no que diz 
Gomes NGL, Pereira FEL. Efeitos da intoxicaçāo crônica com o etanol na evoluçāo da tripanosomiase cruzi experimental no camundongo. Revista da Sociedade Brasileira de Medicina Tropical 22: 191-197, Out-Dez, 1989.

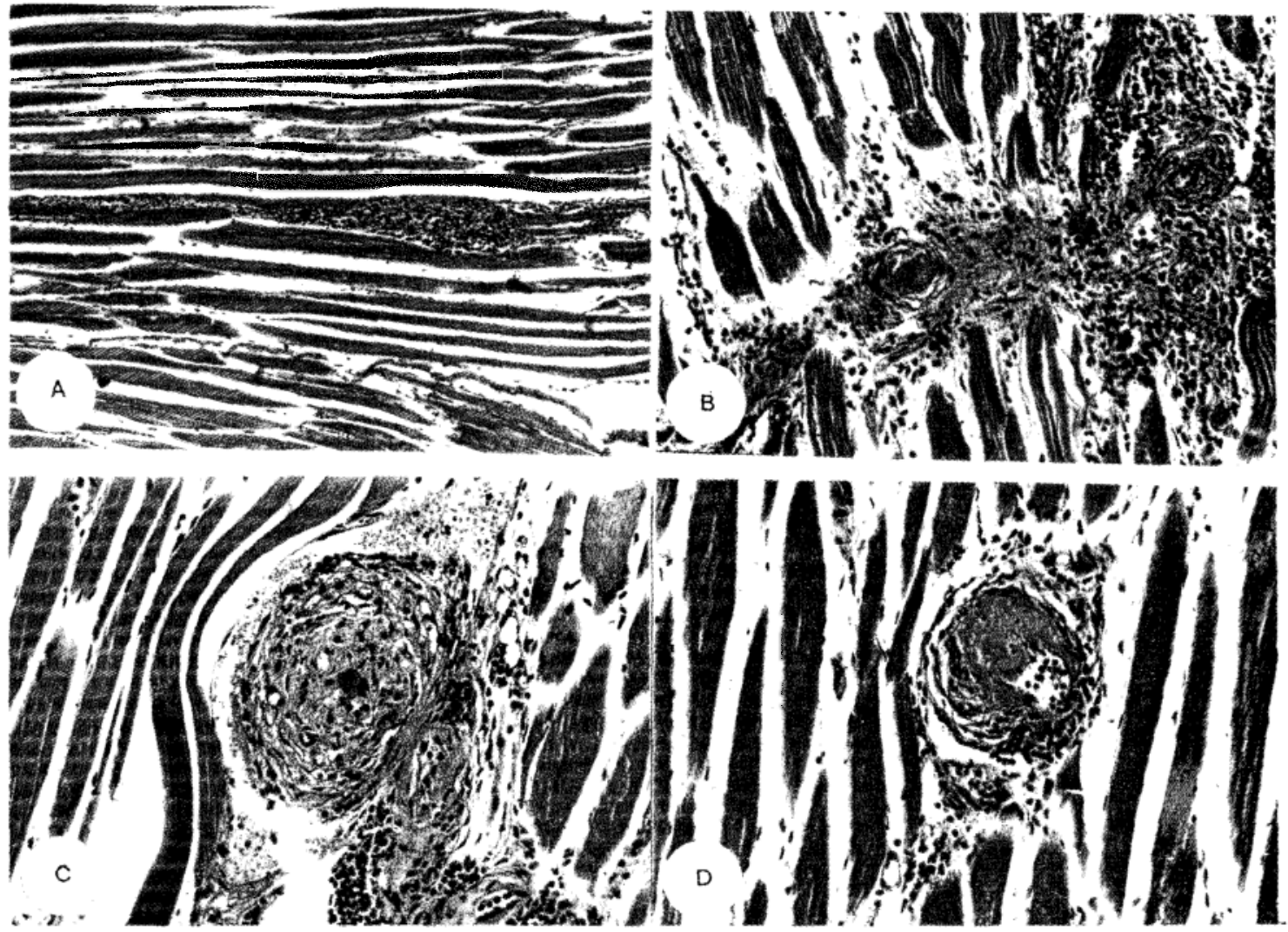

Figura 2 - Músculo esquelético de camundongos infectados com T. cruzi e que não ingeriram etanol. A: Miosite em focos extensos. HE 160X. B: Arterite e periarterite, com trombose hialina em uma arteriola. HE 160X. C: Arterite $e$ periarterite com trombo organizado em uma arteriola. $H E 40 X$. D: Arterite com necrose fibrinóide da parede arteriolar. $\mathrm{HE} 160 \mathrm{X}$

respeito à qualidade e distribuição do exsudato, foram semelhantes àquelas verificadas no grupo apenas infectado examinado na fase crônica (Experimento I). A proliferação fibroblástica no coração foi muito discreta, assim como a vasculite e a perivasculite no músculo esquelético, e em ambos foram também escassos os fenômenos degenerativo-necróticos da inflamação. b) Grupo etanol-T. cruzi II. A inflamação observada, quando comparada com a do grupo anterior, tanto no coração como no músculo esquelético, foi de distribuição e tipo de exsudato semelhantes, entretanto, de menor intensidade, notadamente com relação às lesões vasculares.

O parasitismo tecidual foi escasso, independentemente do uso do etanol.

\section{DISCUSSÃO}

Os resultados dos dois experimentos mostram que a intoxicação crônica com etanol não alterou a mortalidade dos camundongos infectados, quer quando a ingestão foi iniciada após a fase aguda (Experimento I) ou cinco meses antes (Experimento II). Por outro lado, observou-se nos dois experimentos alterações na parasitemia, mais elevada nos animais que ingeriram etanol.

A maior freqüência de parasitemia patente na fase crônica (Experimento I) e parasitemia nitidamente mais elevada na fase aguda (Experimento II) podem ter sido conseqüências de alteraçōes dos mecanismos inespecíficos de defesa ou da resposta imunitária, induzidos pelo uso crônico do etanol.

Existem evidências de que a ingestão crônica de etanol reduz a resistência à infecção bacteriana no homem 136 , admitindo-se que haja interferência do álcool etílico nos mecanismos imunitários. Assim, tem sido descrita, em alcoólatras crônicos, resposta humoral diminuida frente a antígenos $\mathrm{T}$ independentes 18 , havendo, no entanto, diversos relatos mostrando elevação total ou parcial de imunoglobulinas séricas em pacientes etilistas 19212829 . Experimentalmente, demonstrou-se em ratos que a resposta por anticorpos frente a antigenos $\mathrm{T}$ independentes estava aumentada durante a intoxicação alcoólica crônica, mas a resposta a antigenos $T$ dependentes estava significativamente 
Gomes NGL, Pereira FEL. Efeitos da intoxicaçāo crônica com o etanol na evolucão da tripanosomiase cruzi experimental no camundongo. Revista da Sociedade Brasileira de Medicina Tropical 22: 191-197, Out-Dez, 1989.

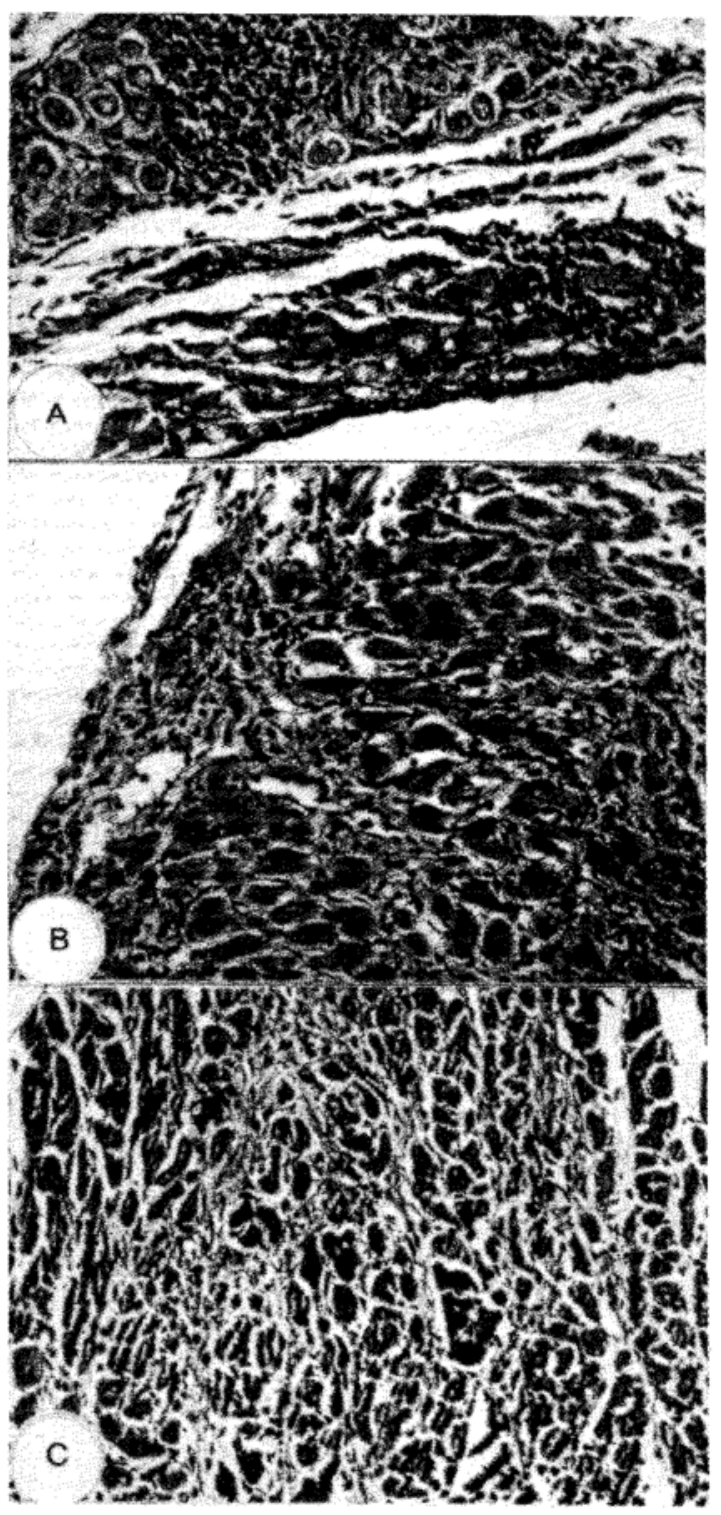

Figura 3 - Coração de camundongos infectados com $\mathrm{T}$. cruzi e tratados com etanol durante seis meses. A: Miocardite no átrio; ganglionite e periganglionite em gânglio epicárdico atrial. HE $160 X$. B: Miocardite no ventriculo direito com exsudato de mononucleares e discreta neoformação conjuntiva. $H E 160 X$. C: Miocardite no ventriculo esquerdo com fibrose peri e endomisial. Tricrômio de Gomori. HE $160 X$.

reduzida 30 dias após o uso do etanol ${ }^{8}$. Por outro lado, a produção de anticorpos antieritrócitos de carneiros foi normal em camundongos intoxicados durante 45 dias ${ }^{15}$. Já a resposta imunitária celular parece estar comprometida, tanto em pacientes alcoólatras crôni$\cos ^{9} 161839$ como em animais experimentalmente in- toxicados com etanol ${ }^{37}$. Camundongos infectados com Schistosoma mansoni e tratados com o etanol formaram granulomas menores do que os controles ${ }^{31}$. Também a atividade do sistema fagocitário mononuclear está diminuida, tanto em alcoólatras crônicos 25 como em camundongos, ratos e coelhos submetidos à

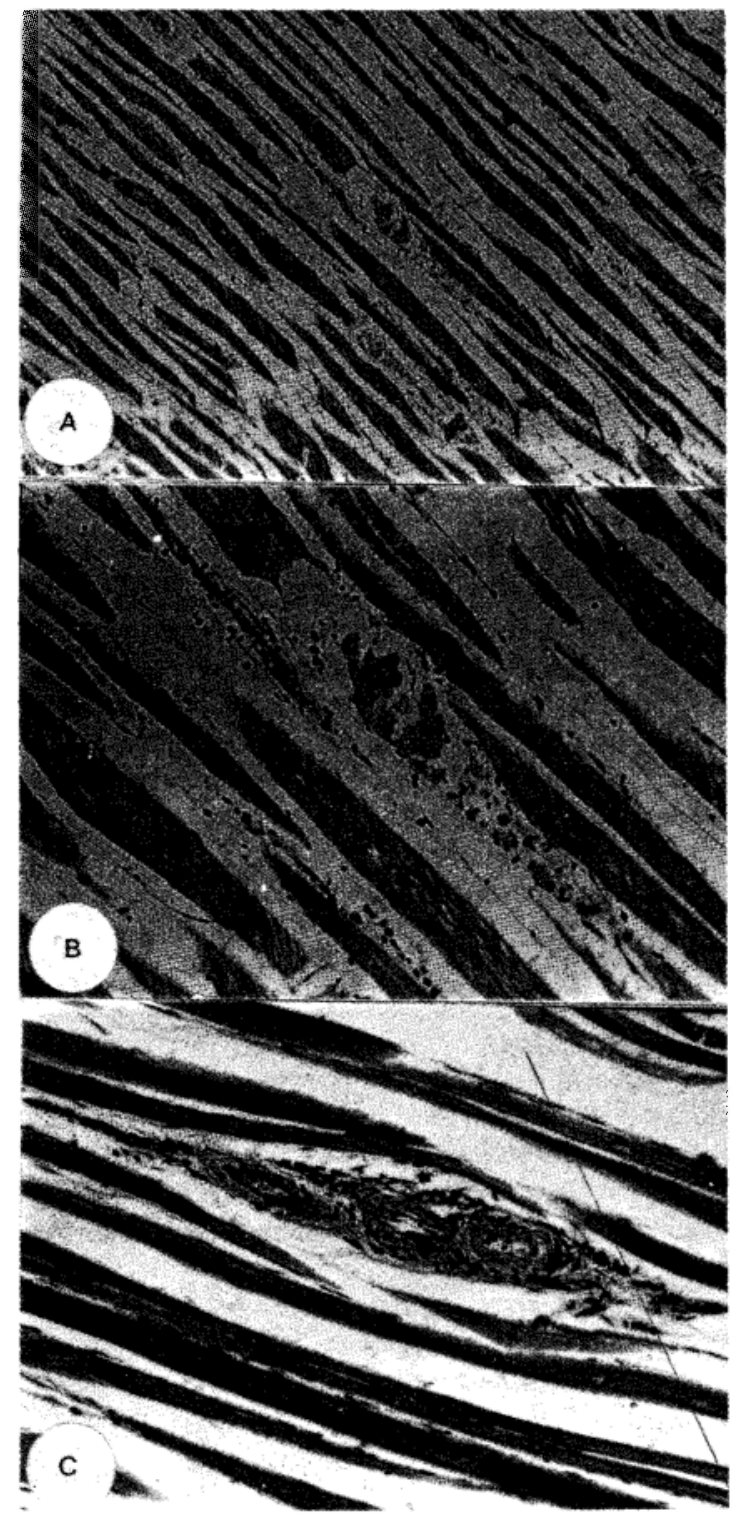

Figura 4 - Músculo esquelético de camundongos infectados com T. cruzi e tratados com etanol durante seis meses. A: Miosite focal com escasso exsudato celular efenômenos regressivos acentuados das fibrocélulas. HE 40X. B: Detalhe da Figura anterior mostrando fibrocélula necrosada com escasso infiltrado inflamatório. $\mathrm{HE} 160 \mathrm{X}$. C: Infiltrado inflamatório discreto em torno e na parede de arteriola. $\mathrm{HE} 160 \mathrm{X}$. 
Gomes NGL, Pereira FEL. Efeitos da intoxicacão crônica com o etanol na evoluçâo da tripanosomiase cruzi experimental no camundongo. Revista da Sociedade Brasileira de Medicina Tropical 22: 191-197, Out-Dez, 1989.

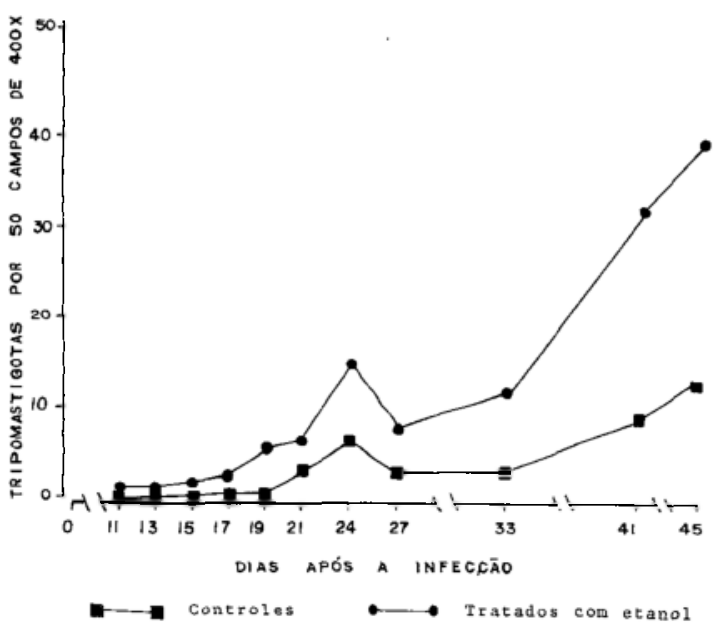

Figura 5 - Parasitemia de camundongos infectados com $\mathrm{T}$. cruzi (16000 tripomastigotas por via i.p.) após terem sido tratados durante cinco meses com etanol (soluçâo a $7 \%$ ).

intoxicação experimental com o etanol 192030 .

É possivel, portanto, que o comprometimento da resposta imunitária e as alterações nos fagócitos possam explicar a maior parasitemia nos animais cronicamente intoxicados com o etanol, embora, este comprometimento não tenha sido suficientemente grande para desequilibrar a relação do parasita com o hospedeiro, razão pela qual a mortalidade foi semethante nos dois grupos.

Nos experimentos aqui relatados, a menor esplenomegalia observada nos animais infectados e tratados com o etanol, foi uma indicação indireta do comprometimento da resposta imunitária induzido pelo álcool etílico.

Quanto às lesões observadas no coração, chamou a atenção a maior neoformação conjuntiva nos animais que receberam o etanol por seis meses após a fase aguda. Burch ${ }^{12}$ descreveu aumento da proliferação fibroblástica no coração de camundongos tratados com etanol a $8 \%$ durante 24 semanas e, no figado, admite-se que o etanol induza maior neoformação de colágeno, indiretamente, pela ativação da prolina hidroxilase devido ao aumento da produção de lactato 24 . No entanto, aumento da produção de lactato no miocárdio, não foi observado em ratos tratados com o etanol 26 .

No músculo esquelético as lesões inflamatórias foram bem menos extensas no grupo que recebeu etanol, apesar dos fenômenos degenerativos mais intensos e da maior freqüência de parasitemia patente neste grupo. É possível que vários mecanismos possam ter contribuido para a menor extensão das lesões inflamatórias no músculo esquelético, entre os quais (a) redução da resposta imunitária celular, a qual parece importante na patogênese das lesōes inflama- tórias na tripanosomiase cruzi; (b) possiveis efeitos antiinflamatórios do etanol ao reduzir a capacidade migratória de fagócitos, especialmente, dos polimorfonucleares 1018 podendo também interferir na ação de alguns mediadores da inflamação 7 (c) alteração nas plaquetas, induzidas pelo etanol, o que explicaria a redução das lesões vasculares (arterite) muito menos freqüentes nos animais intoxicados como o etanol; trombocitopenia e redução da adesividade plaquetária têm sido descritas após o uso do etanol 172223 e nos experimentos aqui relatados foi observado maior tempo de sangramento, no momento de se avaliar a parasitemia, nos animais cronicamente intoxicados com o etanol.

\section{SUMMARY}

The effect of chronic ethyl alcohol intoxication on the evolution of Trypanosoma cruzi infection in mice was studied by two experimental procedures: (1) mice after 60 days of infection with a myotropic strain of $\mathrm{T}$. cruzi were submitted to chronic alcoholic intoxidation receiving a 7\% ethanol solution as only liquid source for six months; (2) mice chronically intoxicated with ethanol during five months were infected with the same strain of $\mathrm{T}$. cruzi and were followed up for 45 days drinking the $7 \%$ alcoholic solution. In comparison with the infected group, not treated with ethanol, the infected mice that received the ethanol showed: a) similar mortality in the two experiments; (b) higher parasitemia in the acute phase and more frequent blood parasites in the chronic phase; (c) myocarditis with less severe cellular exudation but with increased fibrosis; (d) in the skeletal muscle, milder myositis and low frequency of arteritis and hyaline thrombi.

Key-words: Alcoholism and Chagas' disease. Alcoholism. Trypanosoma cruzi.

\section{REFERÊNCIAS BIBLIOGRÁFICAS}

1. Adams HG, Jordan C. Infection in the alcoholic. The Medical Clinics of North America 68:179-200, 1984.

2. Alexander CS, Forsyth GW, Nagasawa HT, Kohlhoff JG. Alcoholic cardiomyopathy in mice. Myocardial glycogen, lipids and certain enzymes. Journal of Molecular and Cellular Cardiology 9:235-245, 1977.

3. Alexander CS, Sekhiri KK, Nagasawa HT. Alcoholic cardiomyopathy in mice. Electron microscopic observations. Journal of Molecular and Cellular Cardiology 9:247-254, 1977.

4. Ali MV, Norlan JP. Alcohol induced depression of reticuloendothelial function in the rat. The Journal of Laboraty and Clinical Medicine 70:295-301, 1967.

5. Almerman EL, Coltart DJ. Alcohol and the heart. British Medical Bulletin 38:77-80, 1982. 
Gomes NGL, Pereira FEL. Efeitos da intoxicação crônica com o etanol na evolucão da tripanosomíase cruzi experimental no camundongo. Revista da Sociedade Brasileira de Medicina Tropical 22: 191-197, Out-Dez, 1989.

6. Askanas A, Udoshi M, Sadjadi SA. The heart in chronic alcoholism: a noninvasive study. American Heart Journal 99:9-16, 1980.

7. Atkinson JP, Sullivan TJ, Kelly JP, Parker CW. Stimulation by alcohols of cyclic AMP metabolism in human leukocytes. Possible role fo cyclic AMP in the anti-inflamatory effects of ethanol. The Journal of Clinical Investigation 60:284-294, 1977.

8. Bagasra O. Howeedy A, Dorio R, Kajdacsy-Balla A. Functional analysis of $\mathrm{T}$ cell subsets in chronic experimental alcoholism immunology 61: 63-69, 1987.

9. Bijorkholm M. Immunological and hematological abnormalities in chronic alcoholism. Acta Medica Scandinavica 207:197-200, 1980.

10. Brayton RG, Stokes PE, Schwartz MS, Loura DB. Effect of alcohol and various diseases on leukocyte mobilization phagocytosis and intracellular bacterial killing. The New England Journal of Medicine 282:123$128,1970$.

11. Brener Z. Contribuição ao estudo da terapeutica experimental da doença de Chagas, Tese. Universidade Federal de Minas Gerais, Belo Horizonte, 1961.

12. Burch GE, Colcolough HL, Harb JM, Tsui CY. The effect of ingestion of ethyl alcohol, wine and beer on the myocardium of mice. The American Journal of Cardiology 27:522-28, 1971.

13. Burch GE, Giles TD. Alcoholic cardiomyopathy. In B Kissin and $\mathrm{H}$ Begleiter: The Biology of Alcoholism. Plenum Press, New York, pp. 435-460, 1974.

14. Cabernite L. O alcoolismo no Brasile as dificuldades na área: Epidemiologia e Prevenção. Jornal Brasileiro de Psiquiatria 31:89-1 12, 1982.

15. Caren LD, Leveque JA, Mandel AD. Effect of ethanol on the immune system in mice. Toxicology Letters 19:147-153, 1983.

16. Carmona A, Merino RA, Melendez M, Tank LV, Reid M, Soto JR, Gonzalez MC, Woff C. Subpoblaciones de linfócitos en alcoholicos con y sin cirrosis. Revista Medica de Chile 108:1108-1104, 1980.

17. Eichner ER. The hematologic disorders of alcoholism. The American Journal of Medicine 54:621-630, 1973.

18. Gluckman SJ, Dvorak VC, MacGregor RR. Host defenses during prolonged alcohol consumption in a controled environment. Archives of Internal Medicine 137:1539-1543, 1977.

19. Green GM, Kass EH. Factors influencing the clearence of bacteria by the lung. Journal of Clinical Investigation 43: 1969.

20. Guarneri JJ, Laurenzi GA. Effect of alcohol on the mobilization of alveolar macrophages. The Journal of Laboratory and Clinical Medicine 72:40-51, 1968.

21. Iturriaga H, Pereda T, Estévez A, Ugarte G. Serum immunoglobulin A changes in alcoholic patients. Annals of Clinical Research 9:39-43, 1977.

22. Larckin EC, Watson-Williams EJ. Alcohol and the blood. The Medical Clinics of North America 68: 105$120,1984$.

23. Lindenbaum J, Hargrove L. Thrombocytopenia in alcoholics. Annals Internal Medicine 68:526-532, 1968.
24. Lindy S, Pedersen FB, Turto H, Uitto J. Lactate dehydrogenase and protocollagen proline hydrocylase in rat skin autograft. Hoppe-Seyler's Zeitschrift fur Physiologische Chemie 352:113-118, 1971.

25. Liu YK. Phagocytic capacity of reticuloendothelial system in alcoholics. Journal of the Reticuloendothelial Society. 25:605-613, 1979.

26. Lochner A, Cowley R, Brink AJ. Effect of ethanol on metabolism and function of perfused rat heart. American Heart Journal 78:770-780, 1969.

27. Lo Grippo GA, Anselm K, Hayashi H. Serum immunoglobulins and five serum proteins in extrahepatic obstructive jaundice and alcoholic cirrhosis. Immunoglobulins and proteins in liver diseases. The American Journal of Gastroenterology 56:357-363, 1971.

28. Lundy J, Raaf JH, Deakins S, Wanebo HJ, Jacobs DA, Lee T, Jacobowitz D, Spear C, Oettgen HF. The acute and chronic effects of alcohol on the human immune system. Surgery Ginecology and Obstetrics 141:212$218,1975$.

29. Manigot DA, Guariento ME, Bastos A, FernandezCamilo MV, Lopes dos Santos TC. Correlação enıtre o consumo de álcool e as manifestações da cardiopatia crônica chagásica. Anais do VI Congresso da Federação Latino-Americana de Parasitólogos. São Paulo. p.178, 1983.

30. Morland B, Morland J. Effects of long term ethanol consumption on rat peritoneal macrophages. Acta Pharmacologica et Toxicologica 50:221-224, 1982.

31. Orrego H, Israel Y, Crossley IR, Mahmoud AA, Peters PA, Varghese G, Wanless IR. Effect of chronic alcohol intake on hepatic fibrosis and granulomas in murine schistosomiasis mansoni. Hepatology 1:416-418, 1981.

32. Pareto Junior RC, Barreto Netto M, Porto MAT, Couto AA, Faria CAC, Silva JBG, Galvão AC, Pinheiro LAF, Cunha VW, Saad E. Miocardiopatia alcoólica. A Folha Médica 83:227-242, 1981.

33. Regan TJ, Ettinger PO, Haider B, Ahmer S, Oldewurtel HA, Lyons MM. The role of ethanol in cardiac disease. Annual Review of Medicine 28:393-409, 1977.

34. Segel LD, Klausner SC, Gnadt JTH, Amsterdam EA. Alcohol and the heart. Medical Clinics of North America 68:147-161, 1984.

35. Segel LD, Rendig SV, Choquet Y, Chacko K, Amsterdam EA, Mason DT. Effects of chronic graded ethanol consumption on the metabolism, ultrastructure, and mechanical function of the rat heart. Cardiovascular Research 9: 649-663, 1975.

36. Smith FE, Palmer DL. Alcoholism, infection and altered host defenses: a review of clinical and experimental observation. Journal of Chronic Diseases 29:35-49, 1976.

37. Tennembaum JI, Ruppert RD, Saint Pierre RL, Greenberger NJ. The effect of chronic alcohol administration on the immune responsiveness of rats. The Journal of Allergy 44:272-281, 1969.

38. Uribarrena R, Maortua M, Rada ED, Crisci CD, Rull S, Borda F, Puente AR Subpoblaciones linfocitarias en pacientes com etilismo crénico. Revista Clinica Española. $156: 431-434,1980$. 